\title{
Immunomodulation for maxillofacial reconstructive surgery
}

\author{
Seong-Gon Kim
}

\begin{abstract}
Immunomodulation is a technique for the modulation of immune responses against graft material to improve surgical success rates. The main target cell for the immunomodulation is a macrophage because it is the reaction site of the graft and controls the healing process. Macrophages can be classified into M1 and M2 types. Most immunomodulation techniques focus on the rapid differentiation of M2-type macrophage. An M2 inducer, 4-hexylresorcinol, has been recently identified and is used for bone grafts and dental implant coatings.
\end{abstract}

Keywords: Immunomodulation, Macrophage, Wound healing, 4-Hexylresorcinol

\section{Background}

The maxillofacial area is composed of several different tissues, including the skin, mucosa, bone, skeletal muscle, and salivary glands. Accordingly, different kinds of graft materials are required for maxillofacial reconstructive surgery. Autogenous graft materials have been considered the optimal choice due to the lack of immunological complications [1]; however, not all patients are free from complications. When the tissue is taken from the donor site, blood circulation is blocked, and hypoxic stress is increased. Additionally, some patients with systemic diseases do not have favorable conditions in the recipient site [2]. These situations can lead to graft necrosis and cause immunological complications, such as serious inflammation.

Most types of grafts are successful in otherwise healthy patients. However, the success rate is lower when patients have pre-existing conditions of systemic diseases, such as diabetes mellitus or osteoporosis [3]. Representative examples may be the application of dental implants. Surface modification technology has been developed to improve osseointegration of dental implant in patients with poor bone quality [4]. Dental implants with rough surfaces generally provide greater opportunities for osseointegration as compared to those with the

\section{Correspondence: kimsg@gwnu.ac.kr}

Department of Oral and Maxillofacial Surgery, College of Dentistry,

Gangneung-Wonju National University, Gangneung, Jukhyun-gil 25457, South Korea

\section{Springer Open}

smooth surfaces [5]. Porosity is an important factor in improving the cell survival of bone grafts [6]. Most of the research involving bone tissue engineering have focused on osteoblasts rather than immune cells such as macrophages [7]. This review may provide a foundation for immunomodulation research.

A recent review summarized the current understanding of immunomodulation in bone grafts or osteoimmunomodulation [8]. Most strategies implementing osteoimmunomodulation have been confined to the modulation of pore- or particle-sized grafts and the change of surface properties. Though these simple modifications have shown success in dental implants $[9,10]$, the precise molecular mechanism has not been clarified. The modification of composition may demonstrate a more advanced level of immunomodulation. However, the addition of nutrient elements, such as magnesium or silicate, does not seem to show significant improvement as compared to the modification of physical properties. Some cytokines or bacterial toxins, such as lipopolysaccharide, are possible ingredients for immunomodulation of bone grafts [11, 12]. However, most protein-based ingredients exacerbate inflammatory responses and have side effects that are difficult to control. To improve the controlled release of ingredients, smart drug carriers have been developed that are designed to release active ingredients as intended [13].

These efforts have dramatically improved the effectiveness of immunomodulation and the design of the drug 
carriers. However, the fundamental mechanism between biomaterial and host response is not well understood. Particularly, the wound healing mechanism is largely unknown. The response to stress-mediated mitochondria may be a key element for understanding these mechanisms. The purpose of this review was to summarize the current level of understanding of macrophages in immunomodulation. Therefore, the application of 4-hexylresorcinol (4HR) in immunomodulation was reviewed in detail.

\section{Main text}

\section{Classical approach for immunomodulation Immunomodulation by changing physical property}

Surface roughness When a graft is implanted into the body, cells attach to the graft surface. Cell response to surface roughness (Fig. 1) has been widely studied in the field of dental implants. Dental implants are installed into the alveolar bone, and the success of osseointegration is dependent on the surface texture of the dental implant. Generally, rough-surfaced implants show better osseointegration as compared to smooth-surfaced implants [5]. As a modification of surface roughness, secretion cytokines favorable to healing are increased by the macrophages [14].

Bone grafts are designed to imitate the surface roughness of the natural bone with $32 \mathrm{~nm}$ grain sizes [15]. Many techniques have been developed to increase the surface roughness of dental implants, which includes sandblasting and acid etching techniques [14]. Dental implant surfaces with M1 polarization impair osseointegration [16]. However, the modification of surface roughness can activate both M1 and M2 types of macrophages and cannot activate any specific type [17].

It is unclear whether hydrophobic or hydrophilic surfaces are better for surface wettability. Hydrophobic surfaces show more intense monocyte-derived immune reactions than hydrophilic surfaces [18]. Also, hydrophilic surfaces are not favorable to macrophage attachment [19]. However, the production of pro-inflammatory cytokines is greatly enhanced on hydrophilic surfaces [20].

Porosity The porosity of the graft is closely associated with oxygen concentration and nutrient supply [9]. Also, highly porous grafts may provide a better opportunity for cellular migration [6]. One study demonstrated that pore size also affects angiogenesis, which is delayed when the pores are smaller $(90-120 \mu \mathrm{m}$ as compared to $300 \mu \mathrm{m})$ [21]. Bone graft material with $80-88 \%$ porosity is better for osteogenesis [6].

\section{Immunomodulation by adding minerals}

The addition of minerals has been used for the development of bone grafts. The bone is mainly composed of hydroxyapatite; therefore, hydroxyapatite-based grafts or coatings have been used for orthopedics and dental implants [22, 23]. Calcium is a major component of hydroxyapatite, and the effect of calcium is concentrationdependent. Calmodulin-dependent kinase responds to
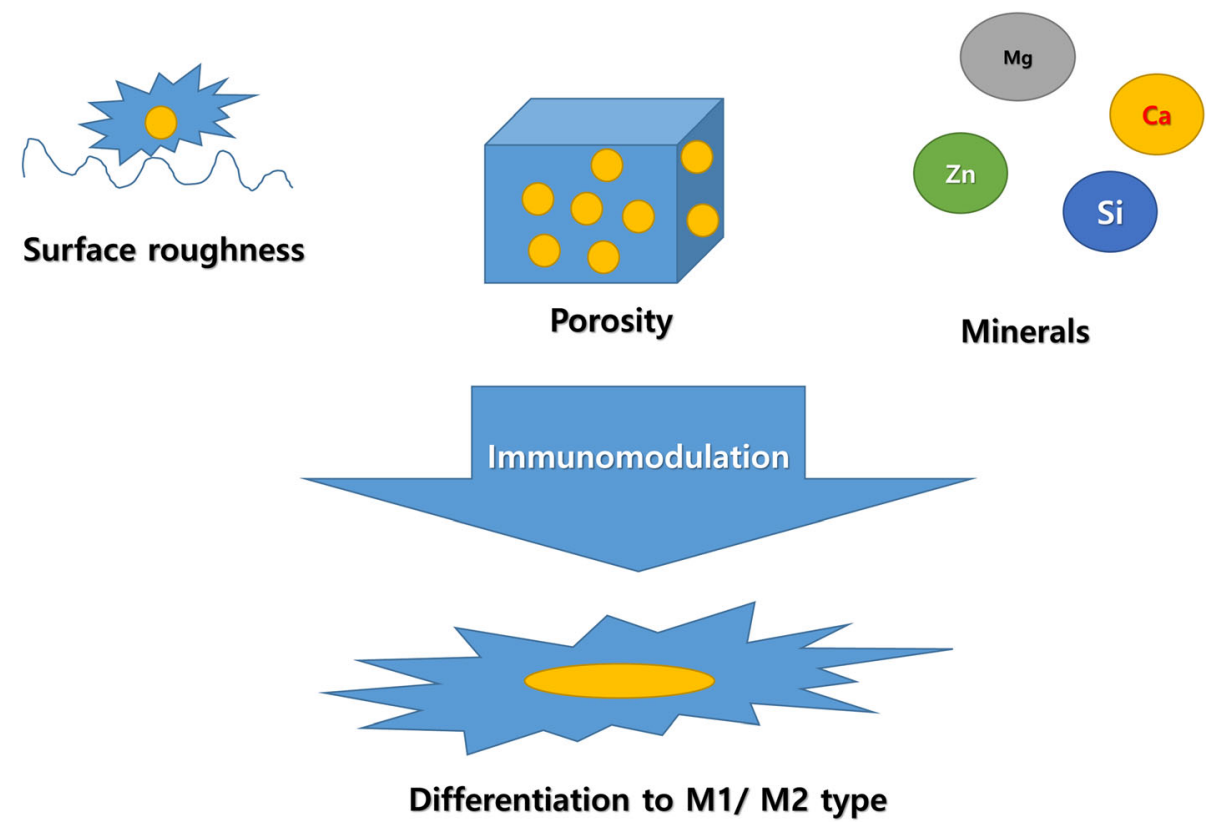

Fig. 1 Classical way of immunomodulation. The immunomodulation technique can be applied to achieve a desirable host response to grafts. Modification of surface roughness and porosity is a simple method for immunomodulation. Some trace elements have also been considered for helping wound healing 
elevated concentrations of calcium ions and activates the nuclear factor-kappa B (NF-kB) pathway and increases inflammation [24]. However, high concentrations of extracellular calcium ions inhibit the NF- $\mathrm{BB}$ pathway via Wingless-int (Wnt) 5A [25].

Many types of trace elements have been used as ingredients for bone grafts. Silicon-based grafts show osteoblast activation [26], and higher concentrations of silicon also suppress osteoclastic activity [27]. Zinc can also increase osteogenesis [28]. Cobalt can be added to promote angiogenesis [29]. Magnesium is added to improve the biodegradability of the graft [30]. Magnesium ions can suppress host immune responses via the inhibition of the toll-like receptor (TLR) signaling pathway [31].

\section{Macrophage and angiogenesis}

Appropriately, timed angiogenesis is essential for normal wound healing, (Fig. 2). Some complications, such as diabetic retinopathy, are caused by impaired angiogenesis [32]. One possible reason of medication-induced jawbone necrosis is impaired angiogenesis after oral surgery [33]. According to a recent publication, the macrophage is a key cell for the healing process and enhances neovascularization via the M1-to-M2 transition [34].

M1-type macrophages are predominant in the inflammatory phase and secrete pro-inflammatory cytokines [35]. The roles of pro-inflammatory cytokines include vasodilation and chemotaxis for recruiting more leukocytes to the wound region [36]. However, M2-type macrophages are predominant in the healing phase. M1-type and M2-type macrophages are generally predominant $1-5$ and 4-10 days after grafting, respectively [37, 38]. The precise mechanism for the M1-to-M2 transition is largely unknown. According to our recent research, antioxidants such as 4HR can induce M2-type macrophages and accelerate angiogenesis [39]. Sequential administration of interferon-gamma (pro-inflammatory cytokine) and interleukin-4 (M2 inducer) increases vascularization of the bone graft [34]. These administrations are redundant and can be simplified, as some inflammation is unavoidable when any graft material is implanted [40]. Thus, presence of an M1 inducer in the graft may not be necessary.

\section{Many types of cytokines and toxins can induce M1/M2 phenotypes}

Macrophage phenotypes, such as M1, M2, or multinucleated giant cells, may be the consequence of survival strategies in response to environmental changes (Fig. 3). Foreign body giant cells (FBGCs) are considered a sign of graft rejection [19]. FBGCs exhibit inflammation associated with cytokines, such as interleukin-1 $\beta$ (IL-1 $\beta)$ and tumor necrosis factor- $\alpha$ (TNF- $\alpha$ ) [19]. However, some studies show that FBGCs express M2 markers [41]. Accordingly, FBGCs may have M1- and M2-type macrophages, including single nuclear macrophages. The body considers grafts to be foreign materials, and an immune reaction is unavoidable. During cellular digestion, some resistant polymers may not be degraded quickly because of size [42], and these materials cannot be digested by a single macrophage. Slower degradation increases reactive oxygen species (ROS), which can induce apoptotic stress in mitochondria. For the survival of macrophages in this environment, increasing the volume of cytoplasm may be an effective strategy for reducing ROS concentrations. Fused macrophages still attempt to degrade grafts [43]; however, fused macrophages show lower enzyme activity as compared to the sum of the unfused group [44]. Lower enzyme activity and diluted ROS are beneficial

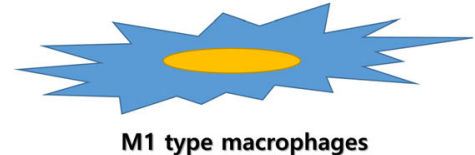

TNF- $\alpha$, MMPs, VEGFs, IL-1 $\beta$

M1 type macrophages

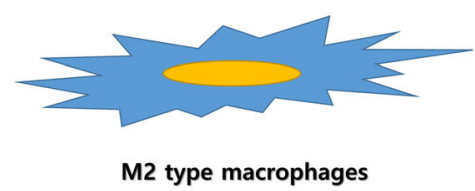

TGF- $\beta 1$, MMPs, VEGFs

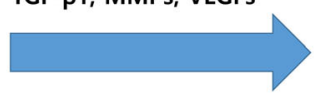

M2 type macrophages

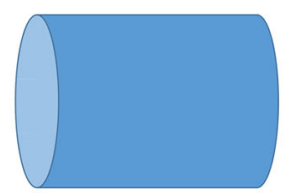

Vasodilatation, permeability $\uparrow$

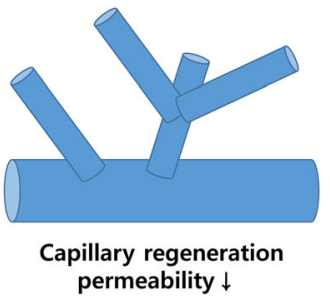

Fig. 2 Role of M1/M2-type macrophages in angiogenesis. M1-type macrophages are responsible for host defenses again invasion. Thus, cytokines secreted from M1-type macrophages recruit leukocytes through vasodilatation and increasing vascular permeability. However, M2-type macrophages are responsible for regeneration. Accordingly, they secrete cytokines for capillary regeneration. Some cytokines are overlapped between $\mathrm{M} 1$ and $\mathrm{M} 2$ macrophages, and their final role is determined by the interaction with other cytokines 


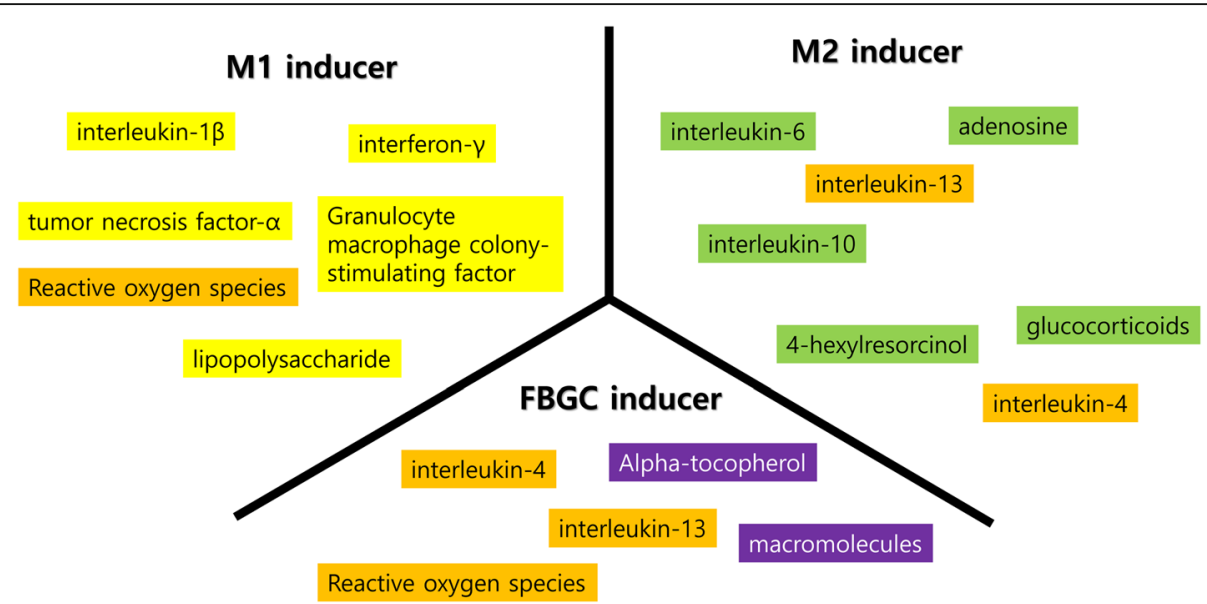

Fig. $3 \mathrm{M} 1 / \mathrm{M} 2 /$ foreign body giant cell (FBGC) inducers. There are many kinds of M1/M2/FBGC inducers. Some of them are not determinant, and the outcome is influenced by the environment

for macrophage survival from apoptotic pressure. When macrophage apoptosis occurs, the FBGC formation is decreased [45]. Some M2 markers respond to cytoplasmic ROS levels, and the expression of these markers in FBGCs seem to be the consequence of cellular fusion. Therefore, M2 marker expression in FBGCs may not be an indicator of normal healing. The artificial fusion of macrophages can be induced by the application of interleukin-4 and interleukin-13 [46].

M1 inducers, such as interferon- $\gamma$ (IFN $\gamma$ ), lipopolysaccharide (LPS), and TNF- $\alpha$ [47], may be required for macrophages to differentiate into the M1 type. Macrophages have many receptors for the detection of foreign materials, such as toll-like receptors [48]. The activation of these receptors induces M1-type macrophages, and M1 macrophages secrete anti-microbial or degrading enzymes [49]. Known M2 inducers are several interleukins including IL-4, IL-10, IL-13, steroid hormones, and 4HR. M2 macrophages are classified as M2a, M2b, and M2c; however, the specificity for these M2 inducers has not been studied extensively. IL-4 and IL-13 are known to induce M2a [50]; however, IL-4 can induce multinucleated giant cells as well [51]. Macrophages are highly responsive to environmental demand, and therefore, their phenotype is highly flexible and reversible $[52,53]$.

\section{Immunomodulation in wound healing}

Following a tissue injury, the epidermis can regenerate, but scar-free healing is still unattainable for skin wounds. Systemic diseases associated with the host immune system and aging may result in impaired wound healing [54, 55], which are related to impaired transitions from M1- to M2-type macrophages [55]. Few organs show true tissue regeneration, and most are regenerated with dense fibrous tissue [56]. Macrophages secrete many kinds of cytokines such as transforming growth factor- $\beta 1$ (TGF- $\beta 1$ ), vascular endothelial growth factor (VEGF), and matrix metalloproteinases (MMPs), and they can activate fibroblasts [57].

There have been several hypotheses for macrophage differentiation. Resident macrophages in most organs are the first line of defense against foreign bodies [58]. Some tissue-resident macrophages may have stem cell-like abilities [59]. When an injury occurs, these macrophages, which are generally M1 type, increase their population and recruit immune cells from the blood [58]. The cytokines expressed by M1-type macrophages are cytotoxic [60]. M1-type macrophages produce ROS and are associated with the immune response against microorganisms [40]. Increased levels of ROS are closely related to apoptosis and phase transformation to either M2-type macrophages or FBGCs. The formation of giant cells is an assumed survival strategy of M1-type macrophages; therefore, FBGCs should produce low levels of ROS [44]. Proliferation and differentiation are mutually exclusive cell developmental stages. The proliferation dominant stage is the inflammatory phase, and its duration is limited by many factors, including the virulence of invading microorganisms, the number of functional immune cells, and the supply of oxygen and nutrients. The interaction among these factors determines the duration of the inflammation [40]. When the cell defense is successful, a disproportionate number of macrophages remain, which leads to apoptotic stress in the macrophages. ROS is mainly produced by M1-type macrophages and induces cell death [61]. Some macrophages undergo apoptosis, while others survive and differentiate into M2-type macrophages. In this stage, most newly visiting macrophages also differentiate into M2-type macrophages. Apoptotic stress can be induced when grafts are too large for digestion. As a survival strategy, macrophages can be fused (Fig. 4). Wound is isolated by macrophages and fibroblasts with dense fibrotic 


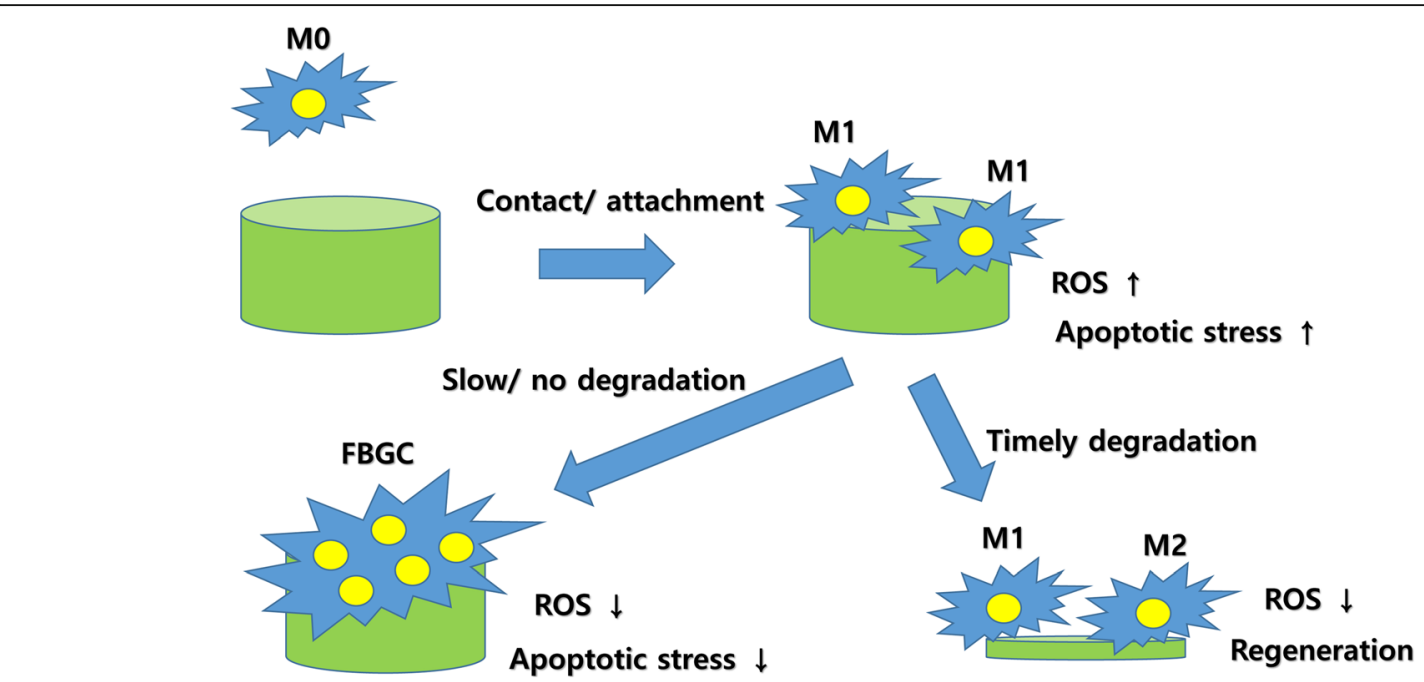

Fig. 4 Hypothesis for M1/M2/foreign body giant cell (FBGC) formation. Cellular stress induced by a foreign body may be the driving force for macrophage differentiation. Reactive oxygen species (ROS) may also be a key factor for macrophage differentiation. Slow or nondegradable grafts accumulate stress in the macrophages. To reduce intracellular stress, increasing the volume of cytoplasm via cellular fusion can be a useful strategy for survival. If the graft is degraded appropriately, intracellular stress is reduced thereafter. M2 transition will occur after reduced stress
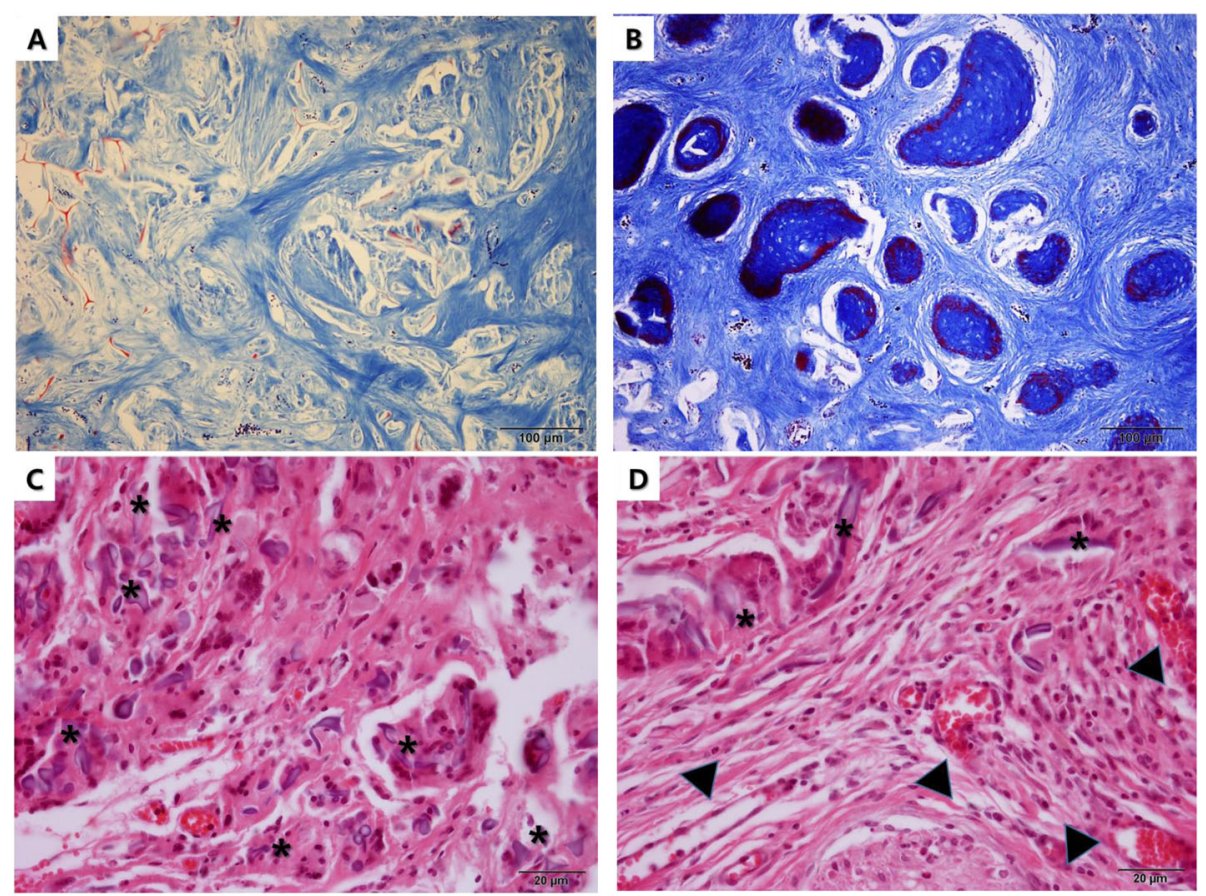

Fig. 5 Accelerated tissue regeneration by incorporating 4-hexylresorcinol (4HR). a Silk and hydroxyapatite grafts were implanted into calvarial defects of rabbits. There was no bone regeneration at 8 weeks postoperation (Masson trichrome stain, original magnification $\times 100$ ). b A silk fibroin, hydroxyapatite, and $4 \mathrm{HR}$ graft were implanted into the calvarial defect of a rabbit. There were numerous osteoid islands at 8 weeks postoperation (Masson trichrome stain, original magnification $\times 100$ ). c A silk fibroin graft was implanted into the dermal pocket of a rat. There were many foreign body giant cells (asterisks) with silk fiber remnants at 12 weeks postoperation (HE stain, original magnification $\times 400$ ). d A silk fibroin and $4 \mathrm{HR}$ graft were implanted into the dermal pocket of a rat. There were few foreign body giant cells (asterisks) at 12 weeks postoperation. Interestingly, capillary regenerations were prominent (arrow heads) (HE stain, original magnification $\times 400)$ 
tissue as defense mechanisms [62]. If isolation occurs, the inside of an infection is transformed from acute to chronic, which is unstable. Accordingly, both M1- and M2-type macrophages may be present in the chronic inflammation. As a consequence, both pro- and antiinflammatory cytokines are found together [40].

\section{4-Hexylresorcinol for the immunomodulation}

$4 \mathrm{HR}$ is an emerging material for use in immunomodulation (Fig. 5). 4HR administered to M2-type macrophages expresses a high level of TGF- $\beta 1[63,64]$. Osteal macrophages (OsteoMacs) produce osteoblast activators, such as TGF- $\beta$ [65], osteopontin [66], and bone morphogenetic protein 2 (BMP-2) [67]. Bone regeneration is significantly impaired without OsteoMacs [68]. The coupled reaction between osteoblasts and osteoclasts and TGF- $\beta$ produced by macrophages are essential for bone remodeling [69, 70]. Generally, M2-type macrophages, including M2a, express TGF- $\beta$ [35, 71]. Anti-inflammatory M2b- and M2c-type macrophages usually express IL-10 [72]. Recently, M2dtype macrophages were introduced and found to secrete TGF- $\beta$, VEGF-A, and TNF- $\alpha$ [73]. M2d-type macrophages are associated with wound healing [73]. When a dental implant is coated with hydroxyapatite with $4 \mathrm{HR}$, bone formation around the implant surface is enhanced [74].
However, function-based discrimination among M2 subtypes is difficult. The spectrum of expressed markers overlaps. Any inducer of M2-type macrophages is considered to be beneficial for graft success [75]. 4HR inhibits the NF- $\kappa B$ pathway [76] and the expression of TNF- $\alpha$ [77]. Accordingly, 4HR-induced M2-type macrophages have M2d characteristics except for TNF- $\alpha$ expression. The limitation of current research regarding $4 \mathrm{HR}$ is that most cellular experiments have been conducted using murine macrophages. Since there is a considerable difference between human macrophages and murine macrophages [78], more specific studies on human macrophages should occur.

4 HR can increase TGF- $\beta 1$ expression in human umbilical vein endothelial cells (HUVEC) (data submitted for publication) and can also increase VEGFs mediated by TGF- $\beta 1$ (data submitted for publication). TGF- $\beta 1$ is an important cytokine in wound healing [79]. Though the downstream signals from TGF- $\beta 1$ are divergent, $4 \mathrm{HR}$ decreases TGF- $\beta 1$ associated inflammatory reactions by inhibiting the NF- $\mathrm{kB}$ pathway [63]. In the diabetic animal model, 4HR ointment showed a substantial increase in capillary regeneration as compared to the untreated control (data submitted for publication).

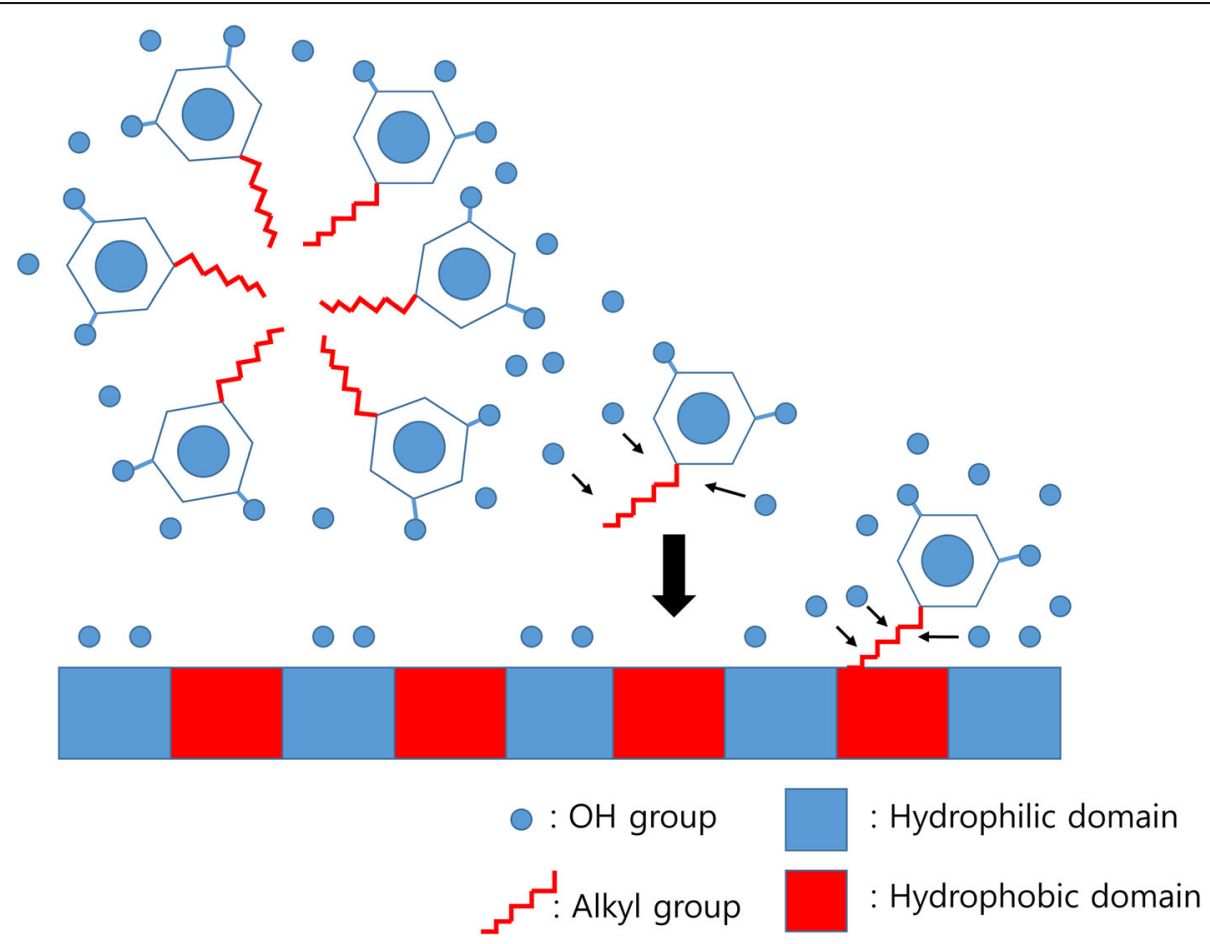

Fig. 6 Smart delivery of 4-hexylresorcinol (4HR) using hydrophobic and hydrophilic domains of silk fibroin. Silk fibroin is a macromolecule composed of hydrophilic and hydrophobic domains. As $4 \mathrm{HR}$ is composed of a long alkyl group (hydrophobic) and 2 hydroxyl groups (hydrophilic), 4HR can be bound to each domain according to its molecular interaction. As hydrophilic interactions are much weaker than hydrophobic interactions, 4HR in the hydrophilic domain of silk fibroin is released first. 4HR in the hydrophobic domain is released during proteolysis 
Role of smart material in the immunomodulation

Controlled release is ideal for optimizing drug effects and minimizing potential side effects. Smart material is designed for controlled release [80]. One example of smart material is $\mathrm{pH}$-responsive polymers. Inflammatory tissue has a lower $\mathrm{pH}$ as compared to the surrounding normal tissue; therefore, low $\mathrm{pH}$ responsive drug carriers could be used as an optimal anti-inflammatory response. Conversely, any per os medication may be protected from degradation caused by gastric acid.

The modification of physical properties is valid only in the early stage of grafting. After initial contact with host cells, the effects on wound healing are limited. However, when active components are released early enough, their effect is observed throughout all healing stages (Fig. 6). Many types of synthetic materials demonstrate slow biodegradation. When these materials are grafted, dense fibrotic tissue is formed within 2-4 weeks [81]. Dense fibrotic tissue has low vascularity, which hampers further degradation. Accordingly, the modification of pore size and shape has been utilized to induce angiogenesis and suppress fibrosis [82]. The most biodegradable polymer has undergone hydrolysis [80, 83], which accounts for the discrepancy between in vitro and in vivo degradation test results. Though the human body is mainly composed of water, slowly degraded polymer is surrounded by dense fibrotic tissue. Dense fibrotic tissue prevents water exchange. Therefore, it is different to in vitro condition such as dipping into water. In our experience, many kinds of biodegradable plates were still found years after installation [84].

Natural macromolecules can be substitutes for synthetic polymers. The collagen-based matrix has been widely tested and used. Collagen is the main component of the extracellular matrix. Scaffold mimics may have an advantage in the transition of macrophage type [85]. Silk fibroin is also used as a drug carrier for controlled release [86]. Compared to the collagen matrix, silk fibroin is a slowly degraded material. Accordingly, the drug release speed of silk fibroin carriers is slower than that of collagen carriers. Based on the target organ and speed of healing, optimal drug carriers can be selected. As $4 \mathrm{HR}$ can accelerate the proteolysis of silk fibroin in a concentrationdependent manner, the drug release speed of the silk fibroin carrier can be modified by adding $4 \mathrm{HR}$.

\section{Conclusion}

Wound healing is influenced by the general health of the patient. To maximize graft success rates, immunomodulation is essential. Many kinds of immunomodulation have been used and studied in maxillofacial reconstructive surgery. $4 \mathrm{HR}$ is a new M2 inducing material that can be applied in various fields of tissue engineering.

\section{Abbreviations}

4HR: 4-Hexylresorcinol; FBGC: Foreign body giant cell; HUVEC: Human

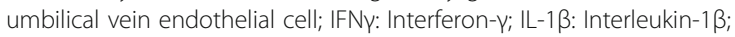
LPS: Lipopolysaccharide; MMP: Matrix metalloproteinase; NF-KB: Nuclear factor-kappa B; OsteoMacs: Osteal macrophages; ROS: Reactive oxygen species; TGF- $\beta 1$ : Transforming growth factor- $\beta 1$; TLR: Toll-like receptor; TNFa: Tumor necrosis factor-a; VEGF: Vascular endothelial growth factor; Wnt: Wingless-int

\section{Acknowledgements}

This study was carried out with the support of "Cooperative Research Program for Agriculture Science and Technology Development (Project no. PJ01313902)" Rural Development Administration, Republic of Korea.

\section{Author's contributions}

The author read and approved the final manuscript.

\section{Funding}

Not applicable.

Availability of data and materials

Not applicable.

Ethics approval and consent to participate

Not applicable.

\section{Consent for publication}

Not applicable.

\section{Competing interests}

The author declares that there are no competing interests.

Received: 23 January 2020 Accepted: 24 February 2020

Published online: 05 March 2020

\section{References}

1. Kang DW, Yun PY, Choi YH, Kim YK (2019) Sinus bone graft and simultaneous vertical ridge augmentation: case series study. Maxillofac Plast Reconstr Surg 41:36

2. Koo CH, Lee JH (2018) Evaluation of mandibular cortical bone ratio on computed tomography images in patients taking bisphosphonates. Maxillofac Plast Reconstr Surg 40:17

3. Kang DW, Kim SH, Choi YH, Kim YK (2019) Repeated failure of implants at the same site: a retrospective clinical study. Maxillofac Plast Reconstr Surg 41:27

4. Kweon H, Lee SW, Hahn BD, Lee YC, Kim SG (2014) Hydroxyapatite and silk combination-coated dental implants result in superior bone formation in the peri-implant area compared with hydroxyapatite and collagen combination-coated implants. J Oral Maxillofac Surg 72:1928-1936

5. Takebe J, Champagne CM, Offenbacher Ishibashi SK, Cooper LF (2003) Titanium surface topography alters cell shape and modulates bone morphogenetic protein 2 expression in the J774A.1 macrophage cell line. J Biomed Mater Res Part A 64:207-216

6. Karageorgiou V, Kaplan D (2005) Porosity of 3D biomaterial scaffolds and osteogenesis. Biomaterials 26:5474-5491

7. Thalji G, Cooper LF (2014) Molecular assessment of osseointegration in vitro: a review of current literature. Int J Oral Maxillofac Implants 29:e171-e199

8. Chen Z, Klein T, Murray RZ, Crawford R, Chang J, Wu C et al (2016) Osteoimmunomodulation for the development of advanced bone biomaterials. Mater Today 19:304-321

9. Laschke MW, Harder Y, Amon M, Martin I, Farhadi J, Ring A et al (2006) Angiogenesis in tissue engineering: breathing life into constructed tissue substitutes. Tissue Eng 12:2093-2104

10. Laquerriere $P$, Grandjean-Laquerriere A, Jallot E, Balossier $G$, Frayssinet $P$, Guenounou M (2003) Importance of hydroxyapatite particles characteristics on cytokines production by human monocytes in vitro. Biomaterials 24 : 2739-2747

11. Wu G, Liu Y, lizuka T, Hunziker EB (2010) The effect of a slow mode of BMP2 delivery on the inflammatory response provoked by bone-defect-filling polymeric scaffolds. Biomaterials 31:7485-7493 
12. Gray A, Maguire T, Schloss R, Yarmush ML (2015) Identification of IL-1 $\beta$ and LPS as optimal activators of monolayer and alginate-encapsulated mesenchymal stromal cell immunomodulation using design of experiments and statistical methods. Biotechnol Prog 31:1058-1070

13. Suarato G, Bertorelli R, Athanassiou A (2018) Borrowing from nature: biopolymers and biocomposites as smart wound care materials. Front Bioeng Biotechnol 6:137

14. Refai AK, Textor M, Brunette DM, Waterfield JD (2004) Effect of titanium surface topography on macrophage activation and secretion of proinflammatory cytokines and chemokines. J Biomed Mater Res A 70:194-205

15. Mendonça G, Mendonça DB, Aragão FJ, Cooper LF (2008) Advancing dental implant surface technology - from micron- to nanotopography. Biomaterials 29:3822-3835

16. Ma QL, Zhao LZ, Liu RR, Jin BQ, Song W, Wang $Y$ et al (2014) Improved implant osseointegration of a nanostructured titanium surface via mediation of macrophage polarization. Biomaterials 35:9853-9867

17. Paul NE, Skazik C, Harwardt M, Bartneck M, Denecke B, Klee D et al (2008) Topographical control of human macrophages by a regularly microstructured polyvinylidene fluoride surface. Biomaterials 29:4056-4064

18. Boehler RM, Graham JG, Shea LD (2011) Tissue engineering tools for modulation of the immune response. Biotechniques 51:239-254

19. Jones JA, Chang DT, Meyerson H, Colton E, Kwon IK, Matsuda T et al (2007) Proteomic analysis and quantification of cytokines and chemokines from biomaterial surface-adherent macrophages and foreign body giant cells. J Biomed Mater Res Part A 83:585-596

20. Yun JK, DeFife K, Colton E, Stack S, Azeez A, Cahalan L et al (1995) Human monocyte/macrophage adhesion and cytokine production on surfacemodified poly(tetrafluoroethylene/hexafluoropropylene) polymers with and without protein preadsorption. J Biomed Mater Res 29:257-268

21. Kuboki Y, Jin Q, Kikuchi M, Mamood J, Takita H (2002) Geometry of artificial ECM: sizes of pores controlling phenotype expression in BMP-induced osteogenesis and chondrogenesis. Connect Tissue Res 43:529-534

22. Eliaz N, Metoki N (2017) Calcium phosphate bioceramics: a review of their history, structure, properties, coating technologies and biomedical applications. Materials (Basel) 10(4):334

23. Lee SW, Hahn BD, Kang TY, Lee MJ, Choi JY, Kim MK et al (2014) Hydroxyapatite and collagen combination-coated dental implants display better bone formation in the peri-implant area than the same combination plus bone morphogenetic protein-2-coated implants, hydroxyapatite only coated implants, and uncoated implants. J Oral Maxillofac Surg 72:53-60

24. De A (2011) Wnt/Ca ${ }^{2+}$ signaling pathway: a brief overview. Acta Biochem Biophys Sin 43:745-756

25. MacLeod RJ, Hayes M, Pacheco I (2007) Wnt5a secretion stimulated by the extracellular calcium-sensing receptor inhibits defective Wnt signaling in colon cancer cells. Am J Physiol Gastrointest Liver Physiol 293:G403-G411

26. Xynos ID, Edgar AJ, Buttery LD, Hench LL, Polak JM (2000) lonic products of bioactive glass dissolution increase proliferation of human osteoblasts and induce insulin-like growth factor II mRNA expression and protein synthesis. Biochem Biophys Res Commun 276:461-465

27. Pietak AM, Reid JW, Stott MJ, Sayer M (2007) Silicon substitution in the calcium phosphate bioceramics. Biomaterials 28:4023-4032

28. Yamaguchi M (1998) Role of zinc in bone formation and bone resorption. J Trace Elem Exp Med 11:119-135

29. Shweiki D, Itin A, Soffer D, Keshet E (1992) Vascular endothelial growth factor induced by hypoxia may mediate hypoxia-initiated angiogenesis. Nature 359:843-845

30. Staiger MP, Pietak AM, Huadmai J, Dias G (2006) Magnesium and its alloys as orthopedic biomaterials: a review. Biomaterials 27:1728-1734

31. Sugimoto J, Romani AM, Valentin-Torres AM, Luciano AA, Ramirez Kitchen CM, Funderburg N et al (2012) Magnesium decreases inflammatory cytokine production: a novel innate immunomodulatory mechanism. J Immunol 188: 6338-6346

32. Capitão M, Soares R (2016) Angiogenesis and inflammation crosstalk in diabetic retinopathy. J Cell Biochem 117:2443-2453

33. Son HJ, Kim JW, Kim SJ (2019) Pharmacoepidemiology and clinical characteristics of medication-related osteonecrosis of the jaw. Maxillofac Plast Reconstr Surg 41:26

34. Spiller KL, Nassiri S, Witherel CE, Anfang RR, Ng J, Nakazawa KR et al (2015) Sequential delivery of immunomodulatory cytokines to facilitate the M1-toM2 transition of macrophages and enhance vascularization of bone scaffolds. Biomaterials 37:194-207
35. Mosser DM, Edwards JP (2008) Exploring the full spectrum of macrophage activation. Nat Rev Immunol 8:958-969

36. Barrientos S, Stojadinovic O, Golinko MS, Brem H, Tomic-Canic M (2008) Growth factors and cytokines in wound healing. Wound Repair Regen 16:585-601

37. Arnold L, Henry A, Poron F, Baba-Amer Y, van Rooijen N, Plonquet A et al (2007) Inflammatory monocytes recruited after skeletal muscle injury switch into antiinflammatory macrophages to support myogenesis. J Exp Med 204 1057-1069

38. Troidl C, Jung G, Troidl K, Hoffmann J, Mollmann H, Nef H et al (2013) The temporal and spatial distribution of macrophage subpopulations during arteriogenesis. Curr Vasc Pharmacol 11:5-12

39. Jo YY, Kim DW, Choi JY, Kim SG (2019) 4-Hexylresorcinol and silk sericin increase the expression of vascular endothelial growth factor via different pathways. Sci Rep 9:3448

40. Kzhyshkowska J, Gudima A, Riabov V, Dollinger C, Lavalle P, Vrana NE. Macrophage responses to implants: prospects for personalized medicine. J Leukoc Biol 98: 953-962 (2015)

41. Vasconcelos DP, Costa M, Amaral IF, Barbosa MA, Aguas AP, Barbosa JN (2015) Modulation of the inflammatory response to chitosan through M2 macrophage polarization using pro-resolution mediators. Biomaterials 37: 116-123

42. Rao AJ, Gibon E, Ma T, Yao Z, Smith RL, Goodman SB (2012) Revision joint replacement, wear particles, and macrophage polarization. Acta Biomater 8: 2815-2823

43. Brodbeck WG, Anderson JM (2009) Giant cell formation and function. Curr Opin Hematol 16:53-57

44. McNally AK, Anderson JM (2011) Macrophage fusion and multinucleated giant cells of inflammation. Adv Exp Med Biol 713:97-111

45. Brodbeck WG, Patel J, Voskerician G, Christenson E, Shive MS, Nakayama Y et al (2002) Biomaterial adherent macrophage apoptosis is increased by hydrophilic and anionic substrates in vivo. Proc Natl Acad Sci U S A 99: 10287-10292

46. Rodriguez A, Macewan SR, Meyerson H, Kirk JT, Anderson JM (2009) The foreign body reaction in T-cell-deficient mice. J Biomed Mater Res Part A 90: 106-113

47. Brown BM, Ratner BD, Goodman SB, Amar S, Badylak SF (2012) Macrophage polarization: an opportunity for improved outcomes in biomaterials and regenerative medicine. Biomaterials 22:3792-3802

48. Takeuchi O, Akira S (2010) Pattern recognition receptors and inflammation. Cell 140:805-820

49. Price JV, Vance RE (2014) The macrophage paradox. Immunity 41:685-693

50. Martinez FO, Sica A, Mantovani A, Locati M (2008) Macrophage activation and polarization. Front Biosci 13:453-461

51. Aghbali A, Rafieyan S, Mohamed-Khosroshahi L, Baradaran B, Shanehbandi D, Kouhsoltani M (2017) IL-4 induces the formation of multinucleated giant cells and expression of $\beta 5$ integrin in central giant cell lesion. Med Oral Patol Oral Cir Bucal 22(1):e1-e6

52. Stout RD, Watkins SK, Suttles J (2009) Functional plasticity of macrophages: in situ reprogramming of tumor-associated macrophages. J Leukoc Biol 86: 1105-1109

53. Porcheray F, Viaud S, Rimaniol AC, Leone C, Samah B, Dereuddre-Bosquet N et al (2005) Macrophage activation switching: an asset for the resolution of inflammation. Clin Exp Immunol 142:481-489

54. Olefsky JM, Glass CK (2010) Macrophages, inflammation, and insulin resistance. Annu Rev Physiol 72:219-246

55. Mahbub S, Deburghgraeve CR, Kovacs EJ (2012) Advanced age impairs macrophage polarization. J Interf Cytokine Res 32:18-26

56. Diegelmann RF, Evans MC (2004) Wound healing: an overview of acute, fibrotic and delayed healing. Front Biosci 9:283-289

57. Wynn TA (2008) Cellular and molecular mechanisms of fibrosis. J Pathol 214 199-210

58. Klopfleisch R (2016) Macrophage reaction against biomaterials in the mouse model - phenotypes, functions and markers. Acta Biomater 43: $3-13$

59. Ginhoux F, Jung S (2014) Monocytes and macrophages: developmental pathways and tissue homeostasis. Nat Rev Immunol 14:392-404

60. van Ginderachter JA, Movahedi K, Hassanzadeh Ghassabeh G, Meerschaut S, Beschin A, Raes $G$ et al (2006) Classical and alternative activation of mononuclear phagocytes: picking the best of both worlds for tumor promotion. Immunobiology 211:487-501 
61. Mills CD (2001) Macrophage arginine metabolism to ornithine/urea or nitric oxide/citrulline: a life or death issue. Crit Rev Immunol 21:399-425

62. Adhyatmika A, Putri KS, Beljaars L, Melgert BN (2015) The elusive antifibrotic macrophage. Front Med 2:81

63. Kim MK, Yoon CS, Kim SG, Park YW, Lee SS, Lee SK (2019) Effects of 4hexylresorcinol on protein expressions in RAW264.7 cells as determined by immunoprecipitation high performance liquid chromatography. Sci Rep 9:3379

64. Miron RJ, Bosshardt DD (2016) OsteoMacs: key players around bone biomaterials. Biomaterials 82:1-19

65. Assoian RK, Fleurdelys BE, Stevenson HC, Miller PJ, Madtes DK, Raines EW et al (1987) Expression and secretion of type beta transforming growth factor by activated human macrophages. Proc Natl Acad Sci U S A 84:6020-6024

66. Takahashi F, Takahashi K, Shimizu K, Cui R, Tada N, Takahashi H et al (2004) Osteopontin is strongly expressed by alveolar macrophages in the lungs of acute respiratory distress syndrome. Lung 182:173-185

67. Champagne CM, Takebe J, Offenbacher S, Cooper LF (2002) Macrophage cell lines produce osteoinductive signals that include bone morphogenetic protein-2. Bone 30:26-31

68. Raggatt $L$, Wullschleger ME, Alexander KA, Wu AC, Millard SM, Kaur S et al (2014) Fracture healing via periosteal callus formation requires macrophages for both initiation and progression of early endochondral ossification. Am J Pathol 184:3192-3204

69. Martin TJ, Sims NA (2005) Osteoclast-derived activity in the coupling of bone formation to resorption. Trends Mol Med 11:76-81

70. Sandberg M, Vuorio T, Hirvonen H, Alitalo K, Vuorio E (1988) Enhanced expression of TGF-beta and c-fos mRNAs in the growth plates of developing human long bones. Development 102:461-470

71. Louis CA, Mody V, Henry WL Jr, Reichner JS, Albina JE (1999) Regulation of arginase isoforms I and II by IL-4 in cultured murine peritoneal macrophages. Am J Phys 276:R237-R242

72. Stout RD, Jiang C, Matta B, Tietzel I, Watkins SK, Suttles J (2005) Macrophages sequentially change their functional phenotype in response to changes in microenvironmental influences. J Immunol 175: 342-349

73. Wang Q, Ni H, Lan L, Wei X, Xiang R, Wang Y (2010) Fra-1 protooncogene regulates IL-6 expression in macrophages and promotes the generation of M2d macrophages. Cell Res 20:701-712

74. Kim SG, Hahn BD, Park DS, Lee YC, Choi EJ, Chae WS et al (2011) Aerosol deposition of hydroxyapatite and 4-hexylresorcinol coatings on titanium alloys for dental implants. J Oral Maxillofac Surg 69(11): e354-e363

75. Goodman SB, Gibon E, Pajarinen J, Lin TH, Keeney M, Ren PG et al (2014) Novel biological strategies for treatment of wear particle-induced periprosthetic osteolysis of orthopaedic implants for joint replacement. J R Soc Interface 11:20130962

76. Kim SG, Lee SW, Park YW, Jeong JH, Choi JY (2011) 4-Hexylresorcinol inhibits NF-KB phosphorylation and has a synergistic effect with cisplatin in KB cells. Oncol Rep 26(6):1527-1532

77. Ahn J, Kim SG, Kim MK, Kim DW, Lee JH, Seok H et al (2016) Topical delivery of 4-hexylresorcinol promotes wound healing via tumor necrosis factor-a suppression. Burns 42(7):1534-1541

78. Schneemann M, Schoeden G (2007) Macrophage biology and immunology: man is not a mouse. J Leukoc Biol 81:579

79. Lichtman MK, Otero-Vinas M, Falanga V (2016) Transforming growth factor beta (TGF- $\beta$ ) isoforms in wound healing and fibrosis. Wound Repair Regen 24(2):215-222

80. Priya James H, John R, Alex A, Anoop KR (2014) Smart polymers for the controlled delivery of drugs - a concise overview. Acta Pharm Sin B 4(2):120-127

81. Anderson JM, Rodriguez A, Chang DT (2008) Foreign body reaction to biomaterials. Semin Immunol 20:86-100

82. Fukano Y, Usui ML, Underwood RA, Isenhath S, Marshall AJ, Hauch KD et al (2010) Epidermal and dermal integration into sphere-templated porous poly(2-hydroxyethyl methacrylate) implants in mice. J Biomed Mater Res A 94:1172-1186

83. Jo YY, Kweon H, Kim DW, Kim MK, Kim SG, Kim JY et al (2017) Accelerated biodegradation of silk sutures through matrix metalloproteinase activation by incorporating 4-hexylresorcinol. Sci Rep 7:42441

84. Park YW (2015) Bioabsorbable osteofixation for orthognathic surgery. Maxillofac Plast Reconstr Surg 37:6
85. Badylak SF, Valentin JE, Ravindra AK, McCabe GP, Stewart-Akers AM (2008) Macrophage phenotype as a determinant of biologic scaffold remodeling Tissue Eng Part A 14:1835-1842

86. Jo YY, Kim SG, Kim MK (2017) Botulinum toxin conjugated with silk fibroin and 4-hexylresorcinol. J Craniofac Surg 28(4):e392-e395

\section{Publisher's Note}

Springer Nature remains neutral with regard to jurisdictional claims in published maps and institutional affiliations.

\section{Submit your manuscript to a SpringerOpen ${ }^{\circ}$ journal and benefit from:}

- Convenient online submission

- Rigorous peer review

- Open access: articles freely available online

- High visibility within the field

- Retaining the copyright to your article

Submit your next manuscript at $\boldsymbol{\nabla}$ springeropen.com 